\title{
A reexamination of krill oil bioavailability studies
}

\author{
Norman Salem Jr ${ }^{*}$ and Connye N Kuratko
}

\begin{abstract}
It has proven difficult to compare the bioavailability of krill oil (KO) vs. fish oil (FO) due to several of the characteristics of $\mathrm{KO}$. These include the lower concentration of the active ingredients, eicosapentaenoic acid (EPA, 20:5n-3) and docosahexaenoic acid (DHA, 22:6n3), in $\mathrm{KO}$ as well as differences in their ratio relative to $\mathrm{FO}$ as well as the red color due to astaxanthin. In addition, the lipid classes in which EPA and DHA are found are quite different with $\mathrm{KO}$ containing phospholipid, di- and tri-glycerides as well as non-esterified fatty acid forms and with FO being primarily triglycerides. No human study has yet been performed that matches the dose of EPA and DHA in a randomized, controlled trial with measures of bloodstream EPA and DHA content. However, several claims have been made suggesting greater bioavailability of KO vs. FO. These have largely been based on a statistical argument where a somewhat lower dose of $\mathrm{KO}$ has been used to result in a similar bloodstream level of EPA and/or DHA or their total. However, the magnitude of the dosage differential is shown to be too small to be expected to result in differing blood levels of the long chain n-3 PUFAs. Some studies which have claimed to provide equal doses of KO and FO have actually used differing amounts of the two major n-3 fatty acid constituents. It is concluded that there is at present no evidence for greater bioavailability of $\mathrm{KO}$ vs. $\mathrm{FO}$ and that more carefully controlled human trials must be performed to establish their relative efficacies after chronic administration.
\end{abstract}

Keywords: Fish oil, Krill oil, Bioavailability, Omega-3 fatty acids

\section{Introduction}

Modern diets particularly in the Western world are largely insufficient in the long chain omega- 3 fatty acids eicosapentaenoic acid (EPA) and docosahexaenoic acid (DHA) [1] leading to sub-optimal organ function and an increased risk of disease [2]. This has led many expert bodies to make recommendations for increasing intakes of these vital nutrients either from an increased seafood intake or via supplements. However, seafood intake in the Western world is low and as a result EPA and DHA intake in the US, for example, is only about 30 and $60 \mathrm{mg} / \mathrm{d}$, respectively, on average [3]. Thus, in order to increase intake of these nutrients, either enriched foods or high quality supplements containing EPA and DHA would be needed by many consumers. Industry has provided fish oils (FO), algal oils and krill oil (KO) capsules to fulfill this requirement. The EPA and DHA delivered in fish oil and algal oil is largely in the form of triglycerides whereas krill oil has triglyceride but also phospholipid and non-esterified fatty acid forms of these nutrients. Recent

\footnotetext{
* Correspondence: norman.salem@dsm.com

Nutritional Lipids, DSM Nutritional Products, 6480 Dobbin Road, Columbia, MD 21045, USA
}

studies such as the one presented by Ramprasath et al. [4] have claimed that EPA and DHA in krill oil are more bioavailable or more efficiently absorbed than EPA/DHA in fish oils, presumably due to the phospholipid form of the lipids in KO. A greater bioavailability would translate into a higher tissue content of EPA and DHA and a resulting greater health benefit. However, it is contended here that this has not in fact been demonstrated due to study design limitations in this and other previous studies, as will be discussed below.

\section{Discussion}

Ramprasath et al. [4] state in their original paper that "none of the studies managed to show improvement in the absorption of $\mathrm{n}-3$ fatty acids with krill oil over fish oil". They criticize the absence of a randomized, controlled trial design and the use of single dose or short term supplementation periods. Clinical studies which are double blinded, randomized and controlled prevent the introduction of biases. It is also not valid to interpret differing absorption characteristics of a single dose or a short term supplementation as relevant to the efficacy of various supplements which are to be given chronically. 
Several of the existing human studies where KO was compared to FO for its ability to change bloodstream fatty acid profiles used such approaches. Faced with the lower content of EPA and DHA in KO relative to FO, researchers did not attempt to provide equivalent fatty acid doses. Rather they provided less EPA/DHA in the KO capsules relative to the FO capsules and then argued that the $\mathrm{KO}$ was more bioavailable when the results showed similar blood levels of EPA and DHA. Table 1 provides a summary of key features of several of these human studies.

One example of this is given by the study of Ulven et al. [5] where three commercial FO capsules containing a total of $864 \mathrm{mg}$ of EPA/DHA were compared to six KO capsules containing a total of $543 \mathrm{mg}$ EPA/DHA over a period of 7 wks; a control group was unsupplemented. Although the subjects, $n=36$ /group, were randomly assigned, they were not blinded as the three study groups were given capsules differing in number and appearance or no capsules for the control group. Groups taking more capsules may be expected to suffer from lower compliance and biases may be introduced in groups taking a capsule of a different color. Not only were the dosages quite different but the ratio of EPA/DHA was different; it was 1.12 in the FO and 1.74 in the KO. Plasma total lipids then showed a significantly increased but equal level of EPA and DHA as well as docosapentaenoic acid (DPAn-3) in the KO and FO groups. It is

Table 1 Study characteristics of comparisons of krill oil and fish oil induced bloodstream fatty acid compositional changes in humans

\begin{tabular}{|c|c|c|c|c|c|c|c|}
\hline \multirow[t]{2}{*}{ Reference } & \multicolumn{2}{|c|}{ Krill oil } & \multicolumn{2}{|c|}{ Fish oil } & \multirow[t]{2}{*}{ Outcome } & \multirow[t]{2}{*}{ Adverse events } & \multirow[t]{2}{*}{ Study limitations } \\
\hline & $\begin{array}{l}\text { EPA } \\
(\mathrm{mg} / \mathrm{d})\end{array}$ & $\begin{array}{l}\text { DHA } \\
(\mathrm{mg} / \mathrm{d})\end{array}$ & $\begin{array}{l}\text { EPA } \\
(\mathrm{mg} / \mathrm{d})\end{array}$ & $\begin{array}{l}\text { DHA } \\
\text { (mg/d) }\end{array}$ & & & \\
\hline \multirow[t]{3}{*}{$\begin{array}{l}\text { Laidlaw } \\
\text { et al. [9] }\end{array}$} & 150 & 90 & As rTG: 650 & As rTG: 450 & $\begin{array}{l}\text { Percent increase in } \\
\text { whole blood fatty acids }\end{array}$ & No serious AEs & Open-label crossover study \\
\hline & & & As EE: 756 & As EE: 228 & $\begin{array}{l}\text { Extrapolation of data } \\
\text { for blood composition } \\
\text { at } 1 \mathrm{~g} \text { fatty acid intake }\end{array}$ & $\begin{array}{l}\text { Other AEs not } \\
\text { specified }\end{array}$ & $\begin{array}{l}\text { EPA/DHA doses varied } \\
\text { according to the lipid source }\end{array}$ \\
\hline & & & As TG: 180 & As TG: 220 & $\begin{array}{l}\text { Estimation of } \\
\text { cardiovascular risk } \\
\text { reduction }\end{array}$ & & $\begin{array}{l}\text { Short period of supplementation } \\
(4 \mathrm{wk})\end{array}$ \\
\hline \multirow[t]{2}{*}{$\begin{array}{l}\text { Maki } \\
\text { et al. [6] }\end{array}$} & 216 & 90 & 212 & 176 & $\begin{array}{l}4 \text { wk supplementation } \\
\text { with } \mathrm{KO} \text {, menhaden oil, } \\
\text { or olive oil }\end{array}$ & No safety-related AEs & Single dosage of EPA + DHA \\
\hline & & & & & $\begin{array}{l}\text { Change in total plasma } \\
\text { fatty acid ( } \mu \mathrm{mol} / \mathrm{L}) \text { from } \\
\text { baseline }\end{array}$ & $\begin{array}{l}\text { Frequency of gas/ } \\
\text { bloating and } \\
\text { flatulence was greater } \\
\text { in } \mathrm{KO} \text { group than in } \\
\mathrm{FO} \text { group }\end{array}$ & $\begin{array}{l}\text { Short period of supplementation } \\
(4 \mathrm{wk})\end{array}$ \\
\hline \multirow[t]{3}{*}{$\begin{array}{l}\text { Ramprasath } \\
\text { et al. }[3,9]\end{array}$} & $\begin{array}{l}493 \\
\text { (calculated) }\end{array}$ & $\begin{array}{l}284 \\
\text { (calculated) }\end{array}$ & $\begin{array}{l}404 \\
\text { (calculated) }\end{array}$ & $\begin{array}{l}260 \\
\text { (calculated) }\end{array}$ & $\begin{array}{l}4 \text { wk supplementation } \\
\text { with } \mathrm{KO}, \mathrm{FO} \text {, or corn oil }\end{array}$ & No safety-related AEs & $\begin{array}{l}\text { LA content was higher in } \mathrm{FO} \\
\text { supplement than in } \mathrm{KO} \\
\text { supplement }\end{array}$ \\
\hline & & & & & $\begin{array}{l}\text { Change in total plasma } \\
\text { and RBC fatty acid (\% }\end{array}$ & $\begin{array}{l}\text { Burping and aftertaste } \\
\text { was greater in } \mathrm{KO}\end{array}$ & $\begin{array}{l}\text { Short period of supplementation } \\
(4 \mathrm{wk})\end{array}$ \\
\hline & & & & & TFA) from baseline & $\begin{array}{l}\text { group than in } \mathrm{FO} \\
\text { group }\end{array}$ & Single dosage of EPA + DHA \\
\hline \multirow[t]{2}{*}{$\begin{array}{l}\text { Schuchardt } \\
\text { et al. [7] }\end{array}$} & 1050 & 630 & $\begin{array}{l}\text { As TG: } \\
1008\end{array}$ & As TG: 672 & $\begin{array}{l}\text { Plasma PL fatty acid at } \\
\text { baseline, } 2,4,6,8,24 \\
48 \text {, and } 72 \text { h after the } \\
\text { one-day intervention }\end{array}$ & $N R$ & Acute supplementation trial \\
\hline & & & As EE: 1008 & As EE: 672 & $\begin{array}{l}\text { Comparisons made as } \\
\text { change from baseline, } \\
\text { area under the curve, } \\
\text { C-max, and t-max }\end{array}$ & & $\begin{array}{l}\text { Crossover design with high } \\
\text { standard deviations }\end{array}$ \\
\hline \multirow[t]{2}{*}{$\begin{array}{l}\text { Ulven et al. } \\
\text { [4] }\end{array}$} & 348 & 195 & 450 & 414 & $\begin{array}{l}7 \text { wk supplementation } \\
\text { with } \mathrm{KO}, \mathrm{FO} \text {, or no } \\
\text { supplementation }\end{array}$ & No safety-related AEs & Intervention was not blinded \\
\hline & & & & & $\begin{array}{l}\text { Change in total plasma } \\
\text { fatty acid }(\mu \mathrm{mol} / \mathrm{L}) \text { from } \\
\text { baseline }\end{array}$ & $\begin{array}{l}\text { Difference in } \\
\text { tolerability not } \\
\text { reported }\end{array}$ & \\
\hline
\end{tabular}

EPA = eicosapentaenoic acid; DHA = docosahexaenoic acid; $\mathrm{KO}=$ krill oil; FO = fish oil; LA = linoleic acid (18:2n-6); \%TFA = percent total fatty acid; RBC = red blood cell; $\mathrm{EE}=$ ethyl ester; $\mathrm{rTG}=$ re-esterified triglyceride; $\mathrm{TG}=$ triglyceride; $\mathrm{AE}$ = adverse event; $\mathrm{NR}$, not reported. 
interesting to note that the $\mathrm{KO}$ group exhibited a significant $12 \%$ increase in arachidonic acid (ARA) whereas the FO group exhibited a $14 \%$ decrease. ARA and its eicosanoid products are important biomediators including their modulation of thrombotic effects and a lowering of ARA in adults is considered beneficial [6]. The authors conclude that "these findings indicate that the bioavailability of n-3 PUFAs from krill oil (mainly PL) is as, or possibly more, efficient as n-3 PUFA from fish oil (TG)".

Similarly Maki et al. [7] in a randomized, controlled study of 76 obese adults given $2 \mathrm{~g} / \mathrm{d}$ of $\mathrm{KO}$, FO or olive oil for 4 wks provided similar amounts of EPA (216 vs. $212 \mathrm{mg} / \mathrm{d}$ ) but more DHA in the FO group (90 vs. $178 \mathrm{mg} / \mathrm{d}$ ). Again the plasma EPA and DHA were significantly increased in both the $\mathrm{KO}$ and FO groups relative to an olive oil control group but the two supplemented groups were the same from a statistical standpoint. It should be noted however that the increased DHA provided in the FO did result in a 66\% greater increase in plasma DHA from the baseline value (149.9 vs. 90.2) relative to the KO group. The baseline values for EPA and particularly for DHA were much higher in the $\mathrm{KO}$ group than control suggesting that there were differences in diet or supplement use in that group relative to other subjects in the study. It is important in this type of study to exclude those subjects who take omega-3 supplements or eat large amounts of fish. It is also a good practice to collect food records or conduct food surveys of the patients in the study to assess omega-3 PUFA intake. This, together with the variability in the study obviated the attainment of statistically significant differences between groups.

In an acute study where $\mathrm{KO}$ was compared to a FO over $72 \mathrm{~h}$ in a cross-over trial in 12 healthy, young men, no statistically significant differences were observed in EPA, DHA or the sum of EPA + DHA in plasma phospholipids after giving a closely matched amount (1680 mg) of EPA/ DHA [8]. There was only a $14 \mathrm{~d}$ wash out between the various legs of this trial and it is questionable whether this period is adequate for wash out. Again, although the authors indicate a double-blinded trial, they provided 14 capsules for the $\mathrm{KO}$ and only 4 capsules for the FO or FO ethyl ester arms. The (probable) difference in color as well as the different number of capsules preclude the possibility of a double-blinded study, potentially introducing bias.

There has been a very recent publication evaluating the efficacy of various sources of long chain omega-3 PUFAs when given at the doses recommended by their manufacturer [9]. This was an open label, randomized, cross-over study of 35 healthy subjects. The following sources were compared with the indicated EPA and DHA contents: concentrated triglyceride EPA 650, DHA 450 mg; fish oil ethyl ester EPA 756, DHA 228 mg; krill oil phospholipid EPA 150, DHA 90 mg; salmon oil triglyceride EPA 180, DHA $220 \mathrm{mg}$. As may be expected, the sources for which larger doses of EPA and DHA were delivered led to a higher content of EPA and DHA in whole blood after a 28 day exposure to the various supplements. For example, the whole blood EPA level was four-fold higher in the subjects given a concentrated triglyceride form of fish oil relative to the $\mathrm{KO}$ group. The authors also comment that various risk factors for cardiovascular disease were reduced best by this concentrated form of omega-3 PUFA but the less concentrated forms like the KO were relatively unsuccessful. Some effort was made to extrapolate the data to a standardized dosage of $1000 \mathrm{mg}$ of EPA + DHA/d but the authors indicate that "because of the difficulties encountered in data extrapolation, i.e. the inaccuracies inherent in the methodology, given the negative results for some subjects, a statistical analysis of this data was not considered to be warranted". They go on to conclude that "'a headto-head comparison of the supplements utilized in this trial, at equivalent doses of EPA + DHA, would be useful in determining their relative bioavailability and their efficacy in increasing blood levels of omega-3 fatty acids, and in reducing CVD risk". In another interesting note, these authors point out that some individuals actually had a decrease in blood EPA and DHA during supplementation indicating that they were not consuming their capsules. Thus the monitoring of compliance by interview, by capsule counts and via fatty acid analysis should always be a feature of these types of clinical trials. The authors suggest that one explanation for the decline in EPA and DHA content in some of these subjects may be due to their habitual intake of high amounts of these nutrients thru seafood in their diets. Once this trial began, they were asked to stop this seafood intake and the amount of EPA and DHA in the supplement was actually less than their previous intake, thus leading to a decline in their blood levels. Here again, it would be important to exclude those subjects consuming large amounts of EPA and DHA thru diet or via supplements.

A recent animal study has also made the claim of greater $\mathrm{KO}$ bioavailability relative to $\mathrm{FO}$ based on providing a lower dose and then finding a statistically similar plasma and liver content of EPA and DHA [10]. In fact, there was again a higher mean content of EPA in both tissues in the FO group with a substantial difference in liver but the differences with respect to $\mathrm{KO}$ did not reach statistical significance as there was considerable variability in measures and a small number of animals in these experimental groups, an $\mathrm{n}=6$.

Ramprasath et al. [4] recognized that previous studies failed to show differences in bioavailability or sustained changes in tissue fatty acid composition after chronic exposure to $\mathrm{FO}$ or $\mathrm{KO}$. They performed a randomized, cross-over trial in 24 healthy young adults over a period of 4 wks. They purported to study the same dose of the 
two preparations and thus confronted the problem of the higher FO content of EPA and DHA by blending the FO with corn oil [11]. Their claim of performing a trial with matched omega- 3 oils is questionable since, as pointed out by Nichols et al. the KO contained $114 \mathrm{mg}$ greater EPA + DHA than the FO dose [12]. According to the data presented by Ramprasath in their Table six, the FO contained $13.5 \%$ of the fatty acids as EPA as compared to $16.4 \%$ in $\mathrm{KO}$ and $8.7 \%$ DHA as compared to 9.5\% in the $\mathrm{KO}$ [4]. This translates, assuming that the same total amount of oil is given in each supplement, to an increase of $22 \%(16.44 / 13.46)$ in the EPA and $9.5 \%$ $(9.46 / 8.66)$ in the DHA in the $\mathrm{KO}$ capsules relative to the FO capsules. That the DPAn-3 was slightly higher in the $\mathrm{FO}$ is not an equalizer since the main parameters to be compared were EPA and DHA as well as their sum in plasma and RBC. It should be apparent then that the doses of EPA/DHA were not the same between study arms.

In summary, the argument put forth in many of the $\mathrm{KO}$ studies is that if a lower dose of $\mathrm{KO}$ is given relative to that in the FO, and if this results in statistically the same EPA or DHA content in the bloodstream, the $\mathrm{KO}$ must have been more bioavailable or more efficacious. This seems to make sense to the non-scientist but is in fact based on a statistical argument. The argument makes the assumption that the differences in EPA/DHA dosage are of a magnitude such that they would be expected to result in a statistically significant difference in mean EPA, DHA or EPA + DHA content in plasma or other blood compartment. However, it is quite common that even very substantial differences in omega-3 dosing, although it may indeed lead to a quite different mean value for EPA or DHA, do not produce a statistically significant difference. Some examples of this are in order. In dose-response studies of FO supplementation, for example, we can compare various doses given within the same study to see how much of an increase in dose is required before an increased mean value of plasma EPA or DHA becomes statistically significant in similarly sized studies.

Barcelo-Coblijn et al. conducted a study of 62 firefighters divided into six experimental groups where the time course of n-3 fatty acid content in RBC was measured biweekly over 12 wks at a daily FO dose of either 0.6 or $1.2 \mathrm{~g} / \mathrm{d}$ [13]. The total RBC $\mathrm{n}-3$ fatty acid content was about the same between these two groups after 2 wks and began to diverge between 4-8 wks only to converge at the same mean value after 10 wks. Although there was a two-fold difference in FO dose, the difference in mean values at the $4 \mathrm{wk}$ time point, for example, was only approximately $7 \%$.

An even more instructive finding was obtained by Flock et al. in a dose-response study of 300, 600, 900 and $1800 \mathrm{mg} / \mathrm{d}$ of FO given daily to 115 healthy men for 5 months with measurements of RBC fatty acid content
[14]. Their data for RBC EPA and DHA content is presented in Table 2. Inspection of this data demonstrates that if 300 and $600 \mathrm{mg} / \mathrm{d}$ FO doses are compared, there is an increase in the mean values for RBC EPA and DHA but these changes are not significantly different. The content of EPA and DHA increase regularly with dose consumed but it is apparent that there is not a linear increase. Note for example the much greater increase in RBC DHA when subjects are given the first $300 \mathrm{mg}$ increment (1.43) than the second such increment (0.30). When the RBC EPA and DHA contents for the 600 and $900 \mathrm{mg} / \mathrm{d}$ doses are compared, there is again no statistical significance to the change in mean values. In this study, differences in $\mathrm{EPA}+\mathrm{DHA}$ dosages of $600 \mathrm{mg} / \mathrm{d}$ were necessary to lead to statistically significant changes in mean values for EPA or DHA, i.e., statistical significance was reached for example between 300 and $900 \mathrm{mg} / \mathrm{d}$ of FO. This is not to indicate that smaller differences in doses cannot lead to significant changes in bloodstream EPA or DHA content in a particular trial. The contention is that the statistical significance of mean differences will depend upon the supplement dose, length of treatment, number of subjects in the groups, compliance with study protocols, control of diets and the variability of analytical measurements. It also points to the conclusion that the most reasonable design for a study comparing two sources of EPA and DHA differing in lipid class is one where identical amounts of both EPA and DHA are given. If one of the sources then produced a statistically different content of EPA or DHA, then a valid claim could be made concerning efficacy or bioavailability. It is important though to note that the differences in the KO vs. FO trials are less than $600 \mathrm{mg}$ and so it is doubtful that one could expect a difference in EPA or DHA content. Therefore, the fact that the final composition of EPA, DHA or EPA + DHA was statistically speaking the same even though in many cases less $\mathrm{KO}$ dose was given, was to be expected and has no implications for bioavailability. Trials based on this premise cannot conclude that $\mathrm{KO}$ is more bioavailable than FO.

Nichols et al. [12] suggested that Ramprasath et al. [4] had introduced an inappropriate variable into their study as the FO capsules contained over $32 \%$ of their fatty acids as linoleic acid (18:2n-6, LA). In a response, Ramprasath et al. [11] indicated that they had blended the FO with corn oil in an attempt to equalize the levels of EPA and DHA in the two oils and conceded that this may have influenced their results. If LA was $32.5 \%$ of the fatty acid and $3 \mathrm{~g}$ of oil were given per day as their publication indicates, this would provide about $975 \mathrm{mg}$ of LA per day in the FO group (only $62 \mathrm{mg}$ in the $\mathrm{KO}$ group). The introduction of this variable is of importance as it is well known that there is an antagonistic effect of raising LA on EPA and DHA content in mammalian tissues [2,6,15]. A simple calculation could then be made using the empirical 


Table $\mathbf{2}$ Effect of multiple doses of fish oil on human erythrocyte EPA and DHA content after $\mathbf{5}$ months of
supplementation
\begin{tabular}{lccccc}
\hline EPA + DHA dose $(\mathbf{m g} / \mathbf{d})$ & $\mathbf{0}$ & $\mathbf{3 0 0}$ & $\mathbf{6 0 0}$ & $\mathbf{9 0 0}$ & $\mathbf{1 8 0 0}$ \\
\hline RBC EPA & $0.47 \pm 0.09^{\mathrm{a}}$ & $0.91 \pm 0.09^{\mathrm{b}}$ & $1.23 \pm 0.10^{\mathrm{bc}}$ & $1.44 \pm 0.09^{\mathrm{c}}$ & $2.46 \pm 0.09^{\mathrm{d}}$ \\
RBC DHA & $3.87 \pm 0.16^{\mathrm{a}}$ & $5.30 \pm 0.16^{\mathrm{b}}$ & $5.60 \pm 0.17^{\mathrm{bc}}$ & $6.06 \pm 0.16^{\mathrm{c}}$ & $7.03 \pm 0.16^{\mathrm{d}}$ \\
\hline
\end{tabular}

Doses which produced a statistically different fatty acid content were denoted by differing superscripts (data from Flock et al. ref 12 ).

equations developed by Lands to estimate how much this factor lowered the values for total n-3 PUFAs in the FO case [15]. What is required for this calculation is the LA, ALA, n-6 HUFA and n-3 HUFA intake values. Since Ramprasath et al. performed their study in Canada, EFA intake values available for Canadian women [16] were used in this calculation. The calculation result is that adding an additional $913 \mathrm{mg}$ of LA in the FO supplement, or about 0.365 en $\%$ LA, produces a $1 \%$ decrease in the $n-3$ expressed as a percentage of total HUFA (highly unsaturated fatty acids). This factor must then be applied to the values given by Ramprasath in their Tables two and three for the "Total n-3 PUFA" in the FO group at the endpoint of the experiment [4]. Applying this correction to these fatty acid values indicates that the FO values for total n-3 PUFA would have been $6.69 \%$ (vs. 6.51\%) in plasma and $8.30 \%$ (vs. 8.04\%) in erythrocytes had not the additional LA been added to the FO capsules. Thus about 26 and $37 \%$ of the differences observed in plasma and erythrocytes, respectively, between $\mathrm{KO}$ and FO could be ascribed to this addition of linoleic acid into the FO. It is unclear whether this would have resulted in a lack of a statistical difference in the EPA and DHA content between the $\mathrm{FO}$ and $\mathrm{KO}$ groups but it would have made observing such a difference less likely.

It has been surmised that $\mathrm{KO}$ may be better absorbed relative to $\mathrm{FO}$ as it is partly comprised of phospholipid whereas FO products are mainly triglycerides. In fact, commercial $\mathrm{KO}$ compositions can vary widely in phospholipid content from as little as $19 \%$ up to $81 \%$ [17]. KO di- and tri-glycerides can vary from about 13 to $34 \%$ and nonesterified fatty acids can vary from 3.5 to as much as $36 \%$. A report of a third commercial KO source indicates that it is composed of only $16 \%$ phospholipid, $24 \%$ triglyceride and $60 \%$ of a "polar, non-phospholipid fraction [18] which is composed mainly of cholesterol, mono- and diglycerides and red pigment, mainly astaxanthin" [19]. Thus two of the three commercial KO preparations had phospholipids as a minor component. Some support can be found in the literature for an increased efficacy for a phospholipid source of PUFAs relative to triglycerides. In a single dosing study, Wijendran et al found a better incorporation of a stable isotope labeled phospholipid containing labeled ARA relative to a triglyceride form [20]. However, such single dose studies cannot be extrapolated to a chronic case where supplements are taken daily and it is unknown whether DHA incorporation into tissues would have a similar sensitivity to the lipid form provided. Only the equilibrium values of these essential fatty acids in tissues are of relevance and clearly related to health effects.

In some of the KO publications, it is stated that there were no adverse effects observed but examination of the data in the papers indicate otherwise. For example, in the Ramprasath study, Table five indicates that subjects in both the corn oil placebo and fish oil groups had one incidence each of burping at a mild and moderate level of intensity [4]. However, there were 4 and 3 incidences at the mild/moderate levels of burping in the $\mathrm{KO}$ arm. Similarly, aftertaste was noted as mild on three occasions in the FO arm but 6 times in the $\mathrm{KO}$ arm and one at the more intense level of moderate. No statistical analyses appear to have been performed and yet the abstract concludes that "krill oil was well tolerated with no adverse effects". It is clear that these are not serious adverse effects but they may well indicate sensory properties that are not up to the standard of commercial FO. Similarly, Maki et al. [7] indicate that the incidence of various gastrointestinal side effects in comparison to menhaden oil are increased, e.g., gas/bloating, 5 vs 0 ; flatulence, 9 vs 2; diarrhea, 5 vs 2 . The authors indicate that the increased incidence of gas/ bloating and flatulence in the $\mathrm{KO}$ group over that observed in the fish oil group was statistically significant. In spite of these observations, the authors state in the abstract that "No significant differences for other safety variables were noted, including adverse events". Here again, these are not serious adverse events but they are indeed adverse events that can affect the quality of life when a supplement is taken chronically.

There has been a recent animal study that has raised some concern about possible KO kidney toxicity [18]. In this study KO was compared to several fish oils (menhaden (MO), salmon (SO) and tuna (TO)) as well as a flaxseed oil (FO) and a corn oil (CO) control after feeding to 4 wk old rats for a subsequent 8 wks as a $12 \%$ fat diet. The authors summarized their findings by saying "Rats fed MO, TO and SO had higher renal DHA and EPA content that may optimize health by reduced inflammation through decreasing production of mediators of inflammation, activation of transcription factors, and inflammatory gene expression. In contrast, rats consuming $\mathrm{KO}$ and to a lesser degree $\mathrm{FO}$ showed evidence of renal calcification and tubulo-interstitial injury. This was due to increased urinary $\mathrm{P}$ excretion associated with the 
phospholipids content of these oil sources. Although further studies are needed, susceptible individual should be aware of a potential risk of increasing phospholipids consumption on renal health". (It is important to state here that within this quotation, the FO is an abbreviation for flaxseed oil and not fish oil). These results were obtained using a diet with $11.8 \mathrm{wt} \%$ as $\mathrm{KO}$ and this is a dose that is unlikely to occur in human diets. Nevertheless, as the authors point out, "use of high doses of purified compounds is standard when assessing the safety of compounds".

In summary, a careful randomized, controlled trial is needed in healthy adults to compare triglyceride forms of long chain, omega-3 PUFAs as found in fish oils to the phospholipid form found in KO. It is necessary to adjust the FO EPA and DHA content to be equivalent to the $\mathrm{KO}$ and to blend them to the same concentration as the $\mathrm{KO}$ so that capsules could be made that match in size and dosage. Furthermore, FO capsules should be colored so that they are similar to the color of KO capsules. A chronic study would then be carried out for at least 4 wks and the primary endpoint being $\mathrm{RBC}$ or plasma fatty acid content of EPA and DHA at the study termination. Control over diet must be exerted to limit fish intake during the trial and subjects with prior omega-3 supplement use or high fish intake must be excluded. Statistical analyses would then be made to determine whether there are differences in EPA/DHA content when an identical dose is given in the two different forms.

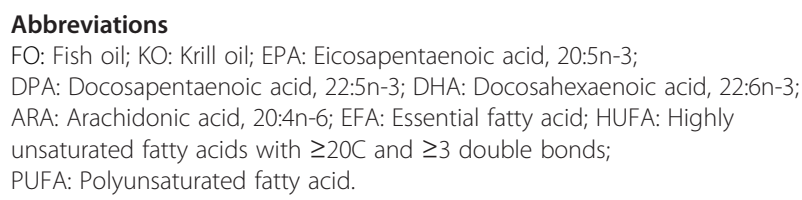

\section{Competing interests}

Dr. Salem is the Corporate Scientist for DSM Nutritional Lipids LLC, a company that produces and sells essential oils including algal and fish oils.

\section{Authors' contributions}

NS evaluated the literature and drafted the manuscript. CNK performed a literature search, analyzed the literature, made one of the tables and helped to draft and edit the manuscript. Both authors read and approved the final manuscript.

Received: 21 May 2014 Accepted: 18 August 2014

Published: 26 August 2014

\section{References}

1. Papanikolaou Y, Brooks J, Reider C, Fulgoni VL II: U.S. adults are not meeting recommended levels of fish and omega-3 fatty acid intake: results of an analysis using observational data from NHANES 2003-2008. Nutr J 2014, 13:31.

2. Hibbeln JR, Nieminen LRG, Blasbalg TY, Riggs JA, Lands WEM: Healthy intakes of $\mathrm{n}-3$ and $\mathrm{n}-6$ fatty acids: estimations considering worldwide diversity. Am J Clin Nutr 2006, 83:1483S-1493S.

3. US Department of Agriculture, Agriculture Research Service: What we eat in America: nutrient intakes from food. In NHANES 2009-2010; Accessed 06 August 2014. http://www.ars.usda.gov/SP2UserFiles/Place/12355000/pdf/ 0910/Table_1_NIN_GEN_09.pdf.
4. Ramprasath VR, Eyal I, Zchut S, Jones PJH: Enhanced increase of omega-3 index in healthy individuals with response to 4-week n-3 fatty acid supplementation from krill oil versus fish oil. Lipids Health Disease 2013, 12:178.

5. Ulven SM, Kirkhus B, Lamglait A, Basu S, Elind E, Haider T, Berge K, Vik H, Pedersen J: Metabolic effects of krill oil are essentially similar to those of fish oil but at lower dose of EPA and DHA, in healthy volunteers. Lipids 2011, 46:37-46.

6. Lands WEM: Diets could prevent many diseases. Lipids 2003, 38:317-321.

7. Maki KC, Reeves MS, Farmer M, Griinari M, Berge K, Vik H, Hubacher R, Rains TM: Krill oil supplementation increases plasma concentrations of eicosapentaenoic and docosahexaenoic acids in overweight and obese men and women. Nutr Res 2009, 29:609-615.

8. Schuchardt JP, Schneider I, Meyer H, Neubronner J, von Schacky C, Hahn A: Incorporation of EPA and DHA into plasma phospholipids in response to different omega-3 fatty acid formulations - a comparative bioavailability study of fish oil vs. krill oil. Lipids Health Dis 2011, 10:145.

9. Laidlaw M, Cockerline CA, Rowe WJ: A randomized clinical trial to determine the efficacy of manufacturers' recommended doses of omega-3 fatty acids from different sources in facilitating cardiovascular disease risk reduction. Lipids Health Dis 2014, 13:99.

10. Tillander V, Bjorndal B, Burri L, Bohov P, Skorve J, Berge RK: Fish oil and krill oil supplementations differentially regulate lipid catabolic and synthetic pathways in mice. Nutr Metab 2014, 11:20.

11. Ramprasath VR, Eyal I, Zchut S, Jones PJH: Response to commentary on a trial comparing krill oil to fish oil. Lipids Health Dis 2014, 13:17.

12. Nichols PD, Kitessa SM, Abeywardena M: Commentary on a trial comparing krill oil versus fish oil. Lipids Health Dis 2014, 13:2.

13. Barcelo-Coblijn G, Murphy EJ, Othman R, Moghadasian MH, Kashour T, Friel JK: Flaxseed oil and fish-oil capsule consumption alters human red blood cell $\mathrm{n}-3$ fatty acid composition: a multiple dosing trial comparing 2 sources of n-3 fatty acid. Am J Clin Nutr 2008, 88:801-809.

14. Flock MR, Skulas-Ray AC, Harris WS, Etherton TD, Fleming JA, Kris-Etherton PM: Determinants of erythrocyte omega-3 fatty acid content in response to fish oil supplementation: A dose-response randomized controlled trial. J Am Heart Assoc 2013, 2:1-13.

15. Lands WEM, Libelt B, Morris A, Kramer NC, Prewitt TE, Bowen P, Schmeisser D, Davidson MH, Burns JH: Maintenance of lower proportions of $(n-6)$ eicosanoid precursors in phospholipids of human plasma in response to added dietary (n-3) fatty acids. Biochim Biophys Acta 1992, 1180:147-162.

16. Denomme J, Stark KD, Holub BJ: Directly quantitated dietary (n-3) fatty acid intakes of pregnant Canadian women are lower than current dietary recommendations. J Nutr 2005, 135:206-211.

17. Araujo P, Zhu H, Breivik JF, Hjelle Jl, Zeng Y: Determination and structural elucidation of triacylglycerols in krill oil by chromatographic techniques. Lipids 2014, 49:163-172.

18. Gigliotti JC, Benedito VA, Livengood R, Oldaker C, Nanda N, Tou JC: Feeding different omega-3 polyunsaturated fatty acid sources influences renal fatty acid composition, inflammation, and occurrence of nephrocalcinosis in femal Sprague-dawley rats. Food Nutr Science 2013, 4:125-136.

19. Gigliotti JC, Davenport MP, Beamer SK, Tou JC, Jaczynski J: Extraction and characterization of lipids from Antartic krill (Euphausia superba). Food Chem 2011, 125:1028-1036.

20. Wijendran V, Huang M-C, Diau G-Y, Boejm G, Nathanielsz PW, Brenna JT: Efficacy of dietary arachidonic acid provided as triglyceride or phospholipid as substrate for brain arachidonic acid accretion in baboon neonates. Pediatr Res 2002, 51:265-272.

doi:10.1186/1476-511X-13-137

Cite this article as: Salem and Kuratko: A reexamination of krill oil bioavailability studies. Lipids in Health and Disease 2014 13:137. 